\title{
Basal Cortisol Levels and Correlates of Hypoadrenalism in Patients with Human Immunodeficiency Virus Infection
}

\author{
Chukwuma O. Ekpebegh $^{a}$ Anthonia O. Ogbera ${ }^{b}$ Benjamin Longo-Mbenza ${ }^{a}$ \\ Ernesto Blanco-Blanco ${ }^{a}$ Ajani Awotedu ${ }^{a}$ Patrick Oluboyo ${ }^{a}$ \\ aDepartment of Internal Medicine, Faculty of Health Sciences, Walter Sisulu University, Mthatha, South Africa; \\ b Department of Medicine, Lagos State University Teaching Hospital, Lagos, Nigeria
}

\section{Key Words}

Hypoadrenalism • Human immunodeficiency virus

infection $\cdot$ Clinical correlates

\begin{abstract}
Objective: To determine the frequency of occurrence of hypoadrenalism in patients with human immunodeficiency virus (HIV) infection and document the clinical correlates of hypoadrenalism for this group of patients. Subjects and Methods: A descriptive study was carried out on 66 hospitalized HIV patients in a semi-urban setting of South Africa. Hypoadrenalism was diagnosed based on a basal cortisol level of less than $400 \mathrm{nmol} / \mathrm{I}$ with or without overt signs and symptoms. Clinical and biochemical parameters of hypoadrenalism were compared between subjects with suboptimal and normal cortisol levels. Statistical analysis included Student's t test, $\chi^{2}$ and Pearson's correlation coefficient tests. Results: The prevalence of hypoadrenalism was $27 \%$ with a high occurrence of contributory factors (cytomegalovirus infection in $100 \%$ and tuberculosis in $68.2 \%$ of the study subjects). Typical features of hypoadrenalism included: hyponatremia, 19.6\%; hyperkalemia, 6.1\%; mucosal hyperpigmentation, $12 \%$, and loss of axillary hair, $15 \%$. Comparison of clinical and biochemical parameters of hypoadrenalism did not show a correlation between CD4 count and cortisol levels ( $r=0.1$
\end{abstract}

and $p=0.3$ ). Conclusion: The prevalence of hypoadrenalism in our patients with HIV infection was high and the clinical features were comparable in subjects with normal and subnormal cortisol levels.

Copyright $\odot 2011$ S. Karger AG, Basel

\section{Introduction}

Human immunodeficiency virus (HIV) infection is a significant risk factor for the occurrence of hypoadrenalism [1]. The burden of HIV infection is high in South Africa, thus making it imperative to identify comorbidities such as hypoadrenalism, which may contribute to the unacceptably high burden of this disorder [1-5]. The presence of tuberculosis, which often occurs in HIV patients, may also contribute to the disease profile. Hypoadrenalism is a potentially modifiable comorbidity, especially as the biochemical abnormality (cortisol deficiency) is readily corrected by cortisol replacement $[3,4]$.

The prevalence of hypoadrenalism in HIV-infected patients ranges from 0.5 to $72 \%[1,3,6-9]$. The commonly reported cause of hypoadrenalism in HIV patients is cytomegalovirus (CMV) infection [6]; other causes include opportunistic infections such as cryptococcosis, Mycobacterium tuberculosis, Mycobacterium avium-in-

\section{KARGER}

Fax +4161306 1234

E-Mail karger@karger.ch

www.karger.com
(C) 2011 S. Karger AG, Basel

1011-7571/11/0206-0525\$38.00/0

Accessible online at:

www.karger.com/mpp
Dr. Anthonia O. Ogbera

Department of Medicine

Lagos State University Teaching Hospital

Ikeja, Lagos (Nigeria)

Tel. +234807595 8085, E-Mail oogbera@yahoo.co.uk 
tracellulare, toxoplasmosis, Pneumocystis carinii, histoplasmosis, blastomycosis and HIV infection [10]. Hypoadrenalism in HIV patients may also be due to involvement of the adrenal glands by Kaposi's sarcoma and lymphoma or hemorrhage resulting from the use of anticoagulants. Drugs such as rifampicin, ketoconazole, opiates and phenytoin that may be indicated in the HIVinfected patient may also be contributory factors in the development of hypoadrenalism.

Although the adrenal gland is the most commonly affected endocrine organ in HIV [11], the clinical diagnosis of hypoadrenalism is made difficult because HIV infection and adrenocortical insufficiency share similar features [12]. The classic clinical features and electrolyte derangements of Addison's disease have been shown to be poorly predictive of hypoadrenalism with regard to HIV infection [11]. Symptoms such as weight loss, malaise, weakness and diarrhea are common to both HIV infection and hypoadrenalism. Hyponatremia, a characteristic feature of hypoadrenalism, is common in HIV infection, where it may be due to inappropriate antidiuretic hormone secretion or gastrointestinal loss resulting from vomiting and diarrhea. Hyperkalemia, another characteristic biochemical feature of hypoadrenalism, can occur as a side effect of cotrimoxazole therapy in HIV patients. A deliberate search for hypoadrenalism will be required to identify hypoadrenalism in HIV patients.

The diagnosis of hypoadrenalism is often carried out by the determination of stimulated cortisol level. However, there are only two published studies on hypocortisolism in HIV patients where diagnosis was based on basal cortisol levels $[8,9]$. Meya et al. [8] noted that the frequency of hypocortisolism in HIV patients was $18.5 \%$ and the defining biochemical parameter was a basal cortisol level below $690 \mathrm{nmol} / \mathrm{l}$. In the other study [9], all subjects with stimulated cortisol levels less than 500 $\mathrm{nmol} / \mathrm{l}$ following administration of $1 \mu \mathrm{g}$ of Synacthen were found to have basal serum cortisol levels below $400 \mathrm{nmol} / \mathrm{l}$. In our practice, a resource-poor setting, Synacthen is not readily available and the diagnosis of hypoadrenalism is usually made by a combination of clinical and biochemical parameters, which include the determination of basal cortisol levels.

Hypoadrenalism is an understudied aspect of this allimportant infection in sub-Saharan Africa which unfortunately is the continent most affected with the burden of HIV infection. The detection and management of hypoadrenalism in HIV infection is a fundamental measure for reducing the morbidity and mortality often documented in this group of patients.
The main objective of this study was to determine the prevalence of basal cortisol levels in patients with HIV infection. Other aims included documentation of the clinical and biochemical correlates of hypoadrenalism in this group of patients.

\section{Subjects and Methods}

This was a cross-sectional study involving 66 consecutive subjects diagnosed with HIV admitted to the medical wards of Nelson Mandela Academic Hospital in the 3-month period from September through November 2009. Ethical approval was sought and obtained from the Ethics Committee of the Faculty of Health Sciences, Walter Sisulu University, Mthatha, South Africa. Patients' age ranged from 17 to 71 years; there were 39 women and 27 men. Inclusion criteria consisted of HIV patients aged $\geq 17$ years who gave their consent for the study. Exclusion criteria included pregnancy, current use of estrogen-containing contraceptives or glucocorticoids.

Information regarding demographics and biodata were collected. The criteria for admission were recorded: past or current evidence of tuberculosis, history of drug use specifically antiretrovirals, antituberculosis drugs, anticonvulsants and antifungals. Participants were questioned for the following symptoms: weight loss, vomiting, diarrhea, dizziness and lethargy.

Clinical examination comprised evaluation of indices of hypocortisolism, including blood pressure measurements, examination of skin and mucous membranes for hyperpigmentation and absence of axillary and pubic hair.

Blood samples for full blood count, electrolytes, urea, creatinine, CD4 count, antibodies to CMV infection and basal cortisol analysis were all taken on the same occasion at 9 a.m. Electrochemoluminescence immunoassay was used to determine cortisol levels; the lower detection limit was $0.500 \mathrm{nmol} / \mathrm{l}$. The intra-assay and interassay coefficients of variation were 1.7 and $2.8 \%$, respectively. The Elecsys Cortisol Assay kit (Roche Diagnostics GmbH, Mannheim, Germany) was used for the assay. Operational definitions were as follows: hypoadrenalism was diagnosed based on basal cortisol levels less than $400 \mathrm{nmol} / \mathrm{l}$ with or without overt signs and symptoms of hypoadrenalism [9]. Hyponatremia and hyperkalemia referred to serum sodium levels of $<136 \mathrm{mmol} / \mathrm{l}$ and potassium levels of $>5.5 \mathrm{mmol} / \mathrm{l}$ [13]. Hypotension was defined by a systolic blood pressure of less than $90 \mathrm{~mm} \mathrm{Hg}$ [8] and CMV infection was based on the detection of immunoglobulin $\mathrm{G}$ or $\mathrm{M}$ antibodies to $\mathrm{CMV}$. Low CD4 count refers to CD4 cells $<200 / \mathrm{mm}^{3}$.

\section{Statistical Analysis}

Statistical analysis was carried out using SPSS version 17 (Chicago, Ill., USA). Quantitative data are expressed as means and standard deviation as well as in quartiles. The means of uniformly distributed continuous and categorical variables were compared with the Student's t test and $\chi^{2}$ test, respectively. Pearson's correlation coefficient analysis was used to determine associations between continuous data. The level of statistical significance was said to be significant with $\mathrm{p}$ values of $\leq 0.05$. 
Table 1. Demographic, clinical and biochemical parameters of the study subjects

\begin{tabular}{lcc}
\hline Variable & Mean \pm SD & Range \\
\hline Age, years & $35.9 \pm 11.9$ & $17-71$ \\
CD4, cells/mm $\mathrm{mm}^{3}$ & $180.2 \pm 186.6$ & $3-837$ \\
Potassium, mmol/l & $4.2 \pm 0.9$ & $2.4-7.10$ \\
Bicarbonate, $\mathrm{mmol} / \mathrm{l}$ & $20.5 \pm 6.1$ & $7-44$ \\
Sodium, mmol/l & $132.9 \pm 5.3$ & $120-145$ \\
Urea, mmol/l & $14.2 \pm 31.4$ & $1-246$ \\
Chloride, $\mathrm{mmol} / \mathrm{l}$ & $96.9 \pm 11.7$ & $19-119$ \\
Creatinine, umol/l & $196.7 \pm 306.7$ & $19-1,732$ \\
Systolic blood pressure, $\mathrm{mm} \mathrm{Hg}$ & $108.6 \pm 17.3$ & $72-164$ \\
Diastolic blood pressure, $\mathrm{mm} \mathrm{Hg}$ & $61.1 \pm 18.1$ & $34-113$ \\
\hline
\end{tabular}

\section{Results}

A summary of the demographic and biochemical parameters is given in table 1 . The clinical features of hypoadrenalism, ranging from lethargy to hyperpigmentation, with the commonly documented sign being loss of axillary hair, are shown in figure 1 . Typical biochemical and hematological parameters of hypoadrenalism, such as hyponatremia, hyperkalemia, and eosinophilia were present in 13/66 (19.6\%), 4/66 (6.1\%) and 30/66 (45.2\%) of patients, respectively.

The mean of basal serum cortisol levels was $586.4 \pm$ $318 \mathrm{nmol} / \mathrm{l}(\mathrm{n}=66)$, with a range of $127-2,069 \mathrm{nmol} / \mathrm{l}$. The prevalence of hypocortisolism was 18/66 (27\%). A comparison of clinical, biochemical and hematological parameters between subjects with hypocortisolemia and those without showed that the majority of all studied parameters were comparable for the two groups (table 2).

All patients $(\mathrm{n}=66)$ were anti-IgG CMV positive, while $45 / 66$ (68.2\%) of patients had current or previous evidence of tuberculosis infection. A comparable proportion of subjects were on antiretroviral therapy or had evidence of tuberculosis regardless of whether the serum cortisol level was low or normal (table 2). Seven of 18 subjects (38.9\%) had low serum cortisol levels versus 22/48 $(45.8 \%)$ patients who had normal cortisol levels on rifampicin therapy $(\mathrm{p}=0.613)$. Cotrimoxazole was administered to $10 / 18(56 \%)$ patients with low serum cortisol versus $21 / 48(43.8 \%)$ patients with normal serum cortisol $(\mathrm{p}=0.392)$. The proportion of patients with low serum cortisol versus normal serum cortisol on fluconazole therapy was $2 / 18(11.1 \%)$ versus $6 / 48(12.5 \%)(p=0.878)$, respectively. Only 2 of the 66 patients were on anticoagu-

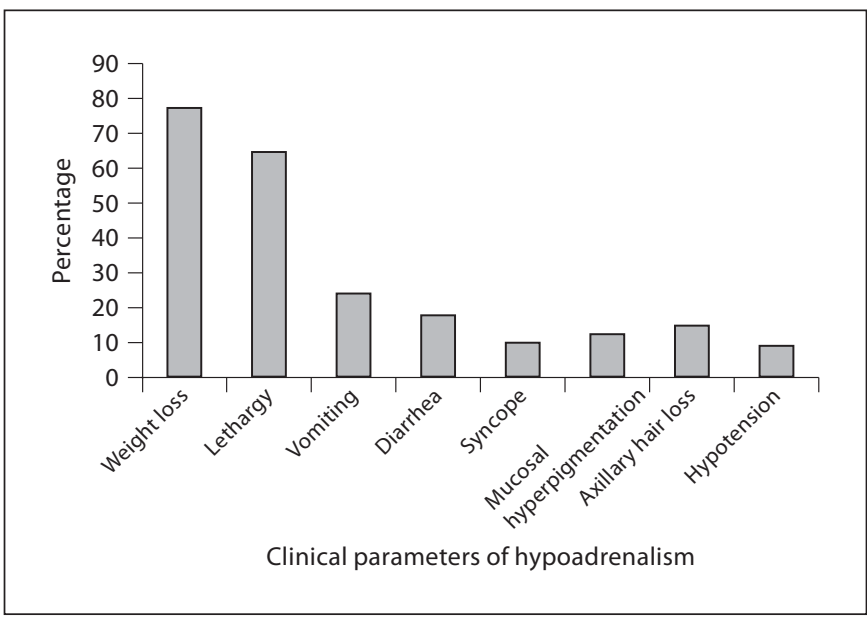

Fig. 1. Distribution of signs and symptoms of hypoadrenalism in HIV patients.

lants or anticonvulsants, respectively; only 1 of all patients received opiates. Low CD4 counts were present in $44(66.7 \%)$ of the patients. There was no significant correlation between cortisol and CD4 count levels $(r=-0.1$, $\mathrm{p}=0.3$ ). The mean CD4 counts between the patients with hypoadrenalism and those without were comparable (585.5 vs. 589.3 cells $/ \mathrm{mm}^{3}, \mathrm{p}=0.3$ ).

\section{Discussion}

In this study, using a cortisol cutoff level of $400 \mathrm{nmol} / \mathrm{l}$, the prevalence of $27 \%$ for hypoadrenalism is higher than $19 \%$ reported in a recent Ugandan study [8] and $19 \%$ in a Brazilian study [14]. The reasons for our higher prevalence of hypoadrenalism in comparison with the Ugandan study [8] which comprised 113 patients and the Brazilian study [14] which included $63 \mathrm{HIV}$-positive patients is not obvious. The high prevalence of CMV infection in our patients $(n=66 / 66)$ may have contributed to our relatively high prevalence of hypoadrenalism. CMV infection was documented in $8.3 \%$ of the Brazilian study [14], but its frequency was not reported in the Ugandan study [8].

Potential contributory comorbidities of adrenalitis, such as tuberculosis and CMV infection, were present in $45 / 66(68.2 \%)$ and $100 / 100(100 \%)$, respectively of the study population. CMV, a $\beta$-herpesvirus, is an important pathogen in patients with AIDS; this pathogen has been shown to be present in over half of those with the disease [15]. It is relevant to note that all the patients studied had 
Table 2. Comparison of the demographic, clinical and biochemical parameters in patients with basal serum cortisol levels of $<400$ and $\geq 400 \mathrm{nmol} / \mathrm{l}$

\begin{tabular}{|c|c|c|c|}
\hline & $\begin{array}{l}\text { Serum cortisol } \\
<400 \mathrm{nmol} / \mathrm{l}\end{array}$ & $\begin{array}{l}\text { Serum cortisol } \\
\geq 400 \mathrm{nmol} / 1\end{array}$ & $\mathrm{p}$ value \\
\hline Age, years & $35.7 \pm 8.7(\mathrm{n}=18)$ & $35.9 \pm 13(n=18)$ & 0.936 \\
\hline Females & $12 / 18(66.7 \%)$ & $27 / 48(56.3 \%)$ & 0.443 \\
\hline CD4 cells per $\mathrm{mm}^{3}$ & $180.6 \pm 195.5(\mathrm{n}=18)$ & $180.1 \pm 185.3(n=48)$ & 0.992 \\
\hline CD 4 count $<200$ cells per $\mathrm{mm}^{3}$ & $13 / 18(72.2 \%)$ & $31 / 48(64.6 \%)$ & 0.558 \\
\hline Patients on antiretrovirals & $5 / 18(27.8 \%)$ & $16 / 48(33.3 \%)$ & 0.666 \\
\hline Weight loss & $11 / 18(61.1 \%)$ & $40 / 48(83.3 \%)$ & 0.06 \\
\hline Lethargy & $8 / 18(44.4 \%)$ & $35 / 48(72.9 \%)$ & 0.031 \\
\hline Vomiting & $5 / 18(27.8 \%)$ & $11 / 48(22.9 \%)$ & 0.682 \\
\hline Diarrhea & $1 / 18(5.6 \%)$ & $11 / 48(22.9 \%)$ & 0.103 \\
\hline Syncope & $1 / 18(5.6 \%)$ & $6 / 48(12.5 \%)$ & 0.414 \\
\hline Evidence of tuberculosis & $7 / 18(38.9 \%)$ & $24 / 48(50 \%)$ & 0.450 \\
\hline Systolic blood pressure $<90 \mathrm{~mm} \mathrm{Hg}$ & $0 / 18(0 \%)$ & $6 / 48(12.5 \%)$ & 0.116 \\
\hline Skin hyperpigmentation & $2 / 18(11.2 \%)$ & $2 / 48(4.2 \%)$ & 0.292 \\
\hline Mucosal hyperpigmentation & $2 / 18(11.2 \%)$ & $6 / 48(12.5 \%)$ & 0.878 \\
\hline Axillary hair loss & $6 / 18(33.3 \%)$ & $40 / 48(41.7 \%)$ & 0.537 \\
\hline Eosinophilia & $9 / 18(50 \%)$ & $21 / 48(43.5 \%)$ & 0.652 \\
\hline Hyponatremia & $4 / 18(22.4 \%)$ & $9 / 48(18.8 \%)$ & 0.752 \\
\hline Hyperkalemia & $2 / 18(11.2 \%)$ & $2 / 48(4.2 \%)$ & 0.292 \\
\hline
\end{tabular}

serological evidence of CMV infection, thus underscoring the need to screen for this infection, especially in Africans with HIV infection.

A CD 4 count below 200 cells $/ \mathrm{mm}^{3}$ was found in $44 / 66$ $(66.7 \%)$ of the study sample. No significant association between cortisol levels and CD4 counts was found, and not surprisingly, the mean CD4 counts were comparable for patients with and without hypoadrenalism. Our results show that 18/66 (27\%) of our patients had hypoadrenalism based on a basal serum cortisol cutoff level of $400 \mathrm{nmol} / \mathrm{l}$ in the presence of several risk factors for hypoadrenalism, i.e. low $\mathrm{CD}$ count, $\mathrm{CMV}$, HIV infection and tuberculosis infection $[6,7,10,15,16]$. A serum cortisol level of $>500 \mathrm{nmol} / \mathrm{l}$, considered indicative of an intact hypothalamic-pituitary-adrenal axis [17], was found in 35/66 (53\%) of our patients. Thus, whether hypoadrenalism was defined according to a basal serum cortisol cutoff of 400 or $500 \mathrm{nmol} / \mathrm{l}$, the proportion of patients with hypoadrenalism was relatively high in relation to the identified risk factors for hypoadrenalism. There was no patient with a serum cortisol level below $100 \mathrm{nmol} / \mathrm{l}$, which has been reported to be indicative of permanent adrenal insufficiency and predictive of lifelong steroid replacement therapy [18].

The lack of significant differences between HIV-infected patients with serum cortisol levels of $<400$ and $\geq 400 \mathrm{nmol} / 1$ with clinical and biochemical features such as syncope, hyperpigmentation, and hyponatremia may have been due to a number of factors. One explanation is the presence of comorbidities such as sepsis, cardiac disease, gastroenteritis and syndrome of inappropriate antidiuretic hormone secretion with features similar to hypoadrenalism. However, gastroenteritis and syndrome of inappropriate antidiuretic hormone secretion are features of hypoadrenalism. It has been argued that acquired cortisol resistance with functional glucocorticoid deficiency occurs with HIV infection [19] and this may be associated with a normal or supranormal cortisol level. We report a comparable frequency of eosinophilia in subjects with subnormal and normal cortisol levels; this observation was also noted by Meya et al. [8].

The findings of this report should be interpreted with caution given the limitations which include small sample size and the fact that hypocortisolemia was evaluated only on the basis of basal and not stimulated cortisol levels.

\section{Conclusion}

Hypoadrenalism was relatively common in our hospitalized HIV patients. Clinical features and CD4 count levels were, however, similar in HIV patients with normal and subnormal cortisol levels. 


\section{References}

1 Marik PE, Kiminyo K, Zaloga GP: Adrenal insufficiency in critically ill patients with human immunodeficiency virus. Crit Care Med 2002;30:1267-1273.

$>2$ Harries AD, Hargreaves NJ, Kemp J, Jindani A, Enarson DA, Maher D, Salaniponi FM: Deaths from tuberculosis in sub-Saharan African countries with a high prevalence of HIV-1. Lancet 2001;357:1519-1523.

-3 Abbot M, Khoo SH, Hammers MR, Wilkins EGL: Prevalence of cortisol deficiency in late HIV disease. J Infect 1995;31:1-4.

$\checkmark 4$ Freda PU, Wardlaw SL, Brudney K, Goland RS: Primary adrenal insufficiency in patients with the acquired immunodeficiency syndrome: a report of five cases. J Clin Endocrinol Metab 1994;79:1540-1545.

$\checkmark 5$ Baker RW, Zumla A, Rook GAW: Tubercolosis, steroid metabolism and immunity. Q J Med 1996;89:387-394.

6 Hoshino Y, Yamashita N, Nakamura T, Iwamoto A: Prospective examination of adrenocortical function in advanced AIDS patients. Endocr J 2002;49:641-647.
7 Yi-Wen H, Ching-Chung C, Hsin-Yun S, Mao-Yuan C, Chen-Ching H, Shan-Chwen C: Primary adrenal insufficiency in patients with acquired immunodeficiency syndrome: report of four cases. J Microbiol Immunol Infect 2004;37:250-253.

-8 Meya DB, Katabira E, Otim M, Ronald A, Colebunders R, Njama D, Mayanja-Kizza H, Whalen CC, Sande M: Functional adrenal insufficiency among critically ill patients with human immunodeficiency virus in a resource limited setting. Afr Health Sci 2007; 7: 101-107.

$>9$ Casodo JL, Piedrola G: Adrenal insufficiency in patients with AIDS: when to suspect it and how to diagnose it. AIDS Patient Care STDS 1997;11:339-343.

10 Mayo J, Collazos J, Martinez E, Ibarra S: Adrenal function in the human immunodeficiency virus infected patient. Arch Intern Med 2002;162:1095-1098.

11 Welch K, Finkbeiner W, Alpers CE, Blumenfeld W, Davis RL, Smuekler EA, Beckstead $\mathrm{JH}$ : Autopsy findings in the acquired immune deficiency syndrome. JAMA 1984;252: 1152-1159.

12 Eledrisi MS, Verhese AC: Adrenal insufficiency in HIV infection. A review and recommendations. Am J Med Sci 2001;321:137144 .
13 Stoner Gregg D: Hyperosmolar, hyperglycaemic state. Am Fam Physician 2005;71: 1624-1628.

14 Wolff F, Nhuch C, Cadore LP, Glitz CL, Hullier FL, Furlanetto TW: Low-dose adrenocorticotropin test in patients with the acquired immunodeficiency syndrome. Braz J Infect Dis 2001;5:53-59.

15 Hoover DR, Saah AJ, Bacellar H, Phair J, Detels R, Anderson R, Kaslow RA: Clinical manifestations of AIDS in the era of pneumocystis prophylaxis. Multicenter AIDS Cohort Study. N Engl J Med 1993;329:19221926.

16 Soule S: Addison's disease in Africa - A teaching hospital experience. Clin Endocrinol 1999;50:115-120.

17 Dorin RI, Qualls CR, Crapo LM: Diagnosis of adrenal insufficiency. Ann Intern Med 2003;139:194-204.

18 Häqq EE, Asplund K, Lithner F: Value of basal plasma cortisol assays in the assessment of pituitary adrenal insufficiency. Clin Endocrinol 1987;26:221-226.

19 Norbiato G, Bevilacqua M, Vago T, Baldi G, Chebat E, Bertora P, Moroni M, Galli M, Oldenburg N: Cortisol resistance in acquired immunodeficiency syndrome. J Clin Endocrinol Metab1992;74:608-613. 